\title{
Lymph node dissection in the resection of gastric cancer: review of existing evidence
}

\author{
Yutaka Tanizawa and Masanori Terashima \\ Division of Gastric Surgery, Shizuoka Cancer Center, 1007 Shimonagakubo, Nagaizumi-cho, Shizuoka 411-8777, Japan
}

\begin{abstract}
Gastric cancer is one of the leading causes of cancer-related death worldwide. Surgery is the only curative therapy for localized gastric cancer, but the extent of regional lymphadenectomy has been a matter of considerable debate. Extended resections that are regarded as standard procedures in some Asian countries, including Japan and Korea, have not been shown to be as effective in Western countries. The extent of lymphadenectomy for advanced gastric cancer has been studied in many prospective randomized controlled trials. On the other hand, patients with early gastric cancer have an excellent survival rate $(>90 \%)$ after radical surgery. Lymph node metastasis from early gastric cancer is relatively infrequent. Therefore, it might be practical to perform less invasive surgery for early gastric cancer. In this review article, we examine the evidence for lymph node dissection as radical surgery in advanced gastric cancer and the possibility of limited resection for early gastric cancer.
\end{abstract}

Key words Gastric cancer · Lymph nodes · Surgery

\section{Introduction}

Gastric cancer is a very common disease worldwide and is the second most frequent cause of cancer death, affecting about one million people per year [1]. Surgery is the most effective and successful method of treatment for gastric cancer, and there is no doubt that systematic lymph node (LN) dissection is the most effective procedure to treat LN metastases of gastric cancer. However, the optimal extent of surgical intervention remains unresolved. Japanese and other Asian surgeons routinely perform an extended (D2) dissection to remove the nodes along the main branches of the celiac axis [2, 3], while many Western surgeons perform more limited (D1) dissection-which removes only the nodal groups

Offprint requests to: $\mathrm{M}$. Terashima

Received: February 13, 2010 / Accepted: May 21, 2010 adjacent to the parts of the stomach removed-because of the absence of randomized controlled trials (RCTs) that favor D2 gastrectomy [4]. Theoretically, the removal of a wider range of LNs by extended LN dissection increases the chances for cure. In fact, the pattern of recurrence after extended surgery is completely different from that after limited surgery and involves locoregional recurrence in the majority of cases [5]. An extended LN dissection might have an influence on the locoregional recurrence rate. However, if the patients have already developed micrometastases or if no LNs are affected, such resection might be irrelevant and harmful, in terms of increased morbidity and mortality.

In this review, we first discuss the current status of the extent of LN dissection for advanced gastric cancer and offer an optimal management approach in view of the results of recent clinical trials.

In contrast with results in patients with advanced gastric cancer, patients with early gastric cancer (EGC) have an excellent survival rate $(>90 \%)$ after radical surgery [6, 7]. Lymph node metastases from EGC are relatively infrequent, and metastases to group $\mathrm{N} 2$ are even rarer [8]. Therefore, it might be appropriate to perform less invasive surgery for EGC. In the latter part of this article, we review limited gastrectomy for EGC.

\section{Surgical anatomy of the gastric lymphatics}

Knowledge of LN node staging is mandatory for understanding the ongoing debate regarding LN dissection. The very complex LNs of the stomach have been arranged into a very useful classification by the Japanese Gastric Cancer Association (JGCA) [9]. According to this classification, 16 different LN compartments (stations) are identified surrounding the stomach. These LN stations are classified into three groups that correspond to the location of the primary tumor and reflect the likelihood of harboring metastases. Most perigastric LNs (stations 1-6) are defined as group N1, whereas the nodes along the left gastric (station 7), common hepatic 


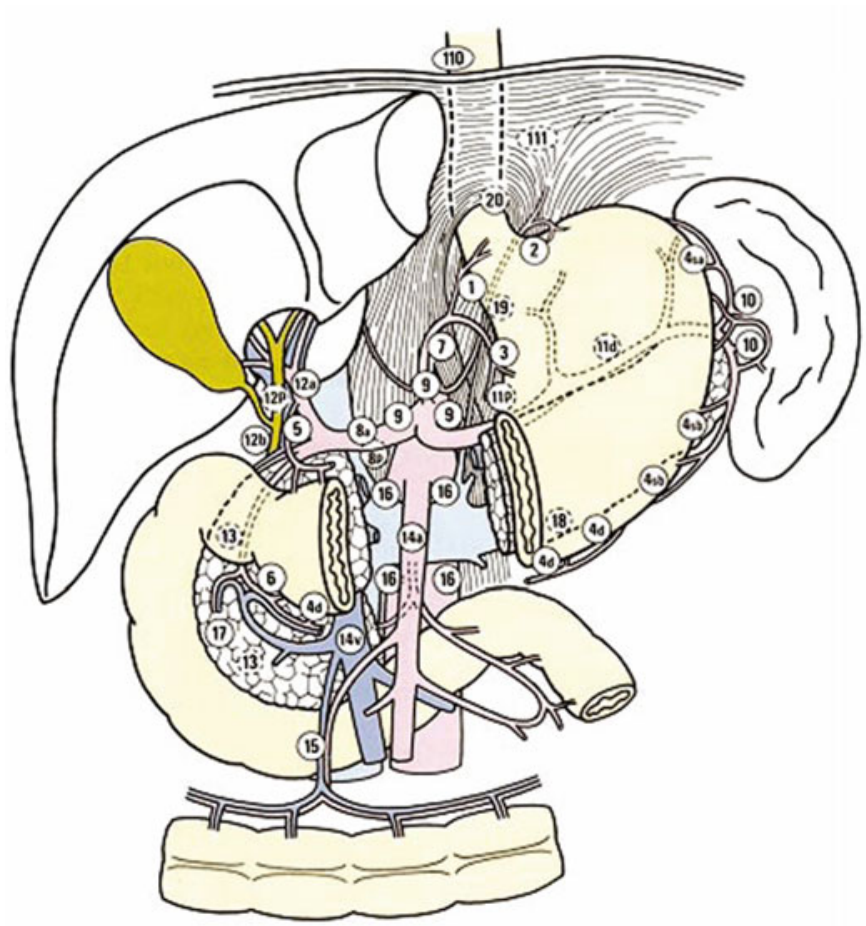

\begin{tabular}{|c|c|}
\hline Station. 1 & Rightparacardial LN \\
\hline Station.2 & Leftparacardial LN \\
\hline Station. 3 & LN along the lesser curvature \\
\hline Station. 4sa & LN along the short gastric vessels \\
\hline Station. $4 \mathrm{sb}$ & LN along the left gastroepiploic vessels \\
\hline Station. 4d & LN along the right gastroepiploic vessels \\
\hline Station. 5 & Suprapyloric LN \\
\hline Station. 6 & InfrapyloricLN \\
\hline Station. 7 & LN along the left gastric artery \\
\hline Station. $8 \mathrm{a}$ & $\begin{array}{l}\text { LN along the common hepatic artery } \\
\text { (Anterosuperior group) }\end{array}$ \\
\hline Station. 8p & $\begin{array}{l}\text { LN along the common hepatic artery } \\
\text { (Posterior group) }\end{array}$ \\
\hline Station. 9 & LN around the celiac artery \\
\hline Station. 10 & LN at the splenic hilum \\
\hline Station $11 p$ & LN along the proximal splenicartery \\
\hline Station. $11 \mathrm{~d}$ & LN along the distal splenic artery \\
\hline Station. $12 \mathrm{a}$ & $\begin{array}{l}\text { LN in the hepatoduodenal ligament } \\
\text { (along the hepatic artery) }\end{array}$ \\
\hline Station. $12 b$ & $\begin{array}{l}\text { LN in the hepatoduodenal ligament } \\
\text { (along the bile duct) }\end{array}$ \\
\hline Station. $12 p$ & $\begin{array}{l}\text { LN in the hepatoduodenal ligament } \\
\text { (behind the portal vein) }\end{array}$ \\
\hline Station. 13 & LN on the posterior surface of the pancreatic head \\
\hline Station. 14v & LN along the superiormesenteric vein \\
\hline Station. 14a & LN along the superior mesenteric artery \\
\hline Station. 15 & LN along the middle colic vessels \\
\hline Station. 16a1 & LN in the aortic hiatus \\
\hline Station. 16a2 & $\begin{array}{l}\text { LN around the abdominal aorta } \\
\text { (from the upper margin of the celiac trunk } \\
\text { to the lower margin of the left renal vein) }\end{array}$ \\
\hline Station 16b1 & $\begin{array}{l}\text { LN around the abdominal aorta } \\
\text { (from the lower marginof the left renal vein } \\
\text { to the unper margin of the inferior mesenteric artery) }\end{array}$ \\
\hline Station. $16 \mathrm{~b} 2$ & $\begin{array}{l}\text { LN around the abdominal aorta } \\
\text { (from the upper margin of the inferior mesentericartery } \\
\text { to the aortic bifurcation) }\end{array}$ \\
\hline Station. 17 & LN on the anterior surface of the pancreatic head \\
\hline Station. 18 & LN along the inferior marginof the pancreas \\
\hline Station. 19 & InfradiaphragmaticLN \\
\hline Station. 20 & LN in the esophageal hiatus of the diaphragm \\
\hline Station. 110 & Paraesophageal LN in the lower thorax \\
\hline Station. 111 & Supradiaphragmatic LN \\
\hline Station. 112 & Posterior mediastinal LN \\
\hline
\end{tabular}

Fig. 1. Lymph node station numbers according to the Japanese classification of gastric carcinoma 2nd English edition reproduced from [9], with permission. $L N$, Lymph node

(station 8), splenic (station 11), and proper hepatic (station 12) arteries and along the celiac axis (station 9) are defined as group N2. Minor modifications of this schedule occur depending on the location of the primary tumor (Fig. 1). For example, the LNs at the splenic hilum (station 10) also belong to group N2 when the tumor is located in the proximal stomach. The paraaortic LNs (station 16) are defined as group N3.

\section{D1 versus D2 or D3 trials}

Five RCTs comparing D1 and D2/D3 dissection have been performed. There have been two large-scale RCTs $[10,11]$, two small-scale RCTs $[12,13]$, and 1 smallinstitution trial [14]. Three major RCTs and one ongoing RCT [15] are summarized in Table 1.

\section{Dutch Gastric Cancer Group trial}

The Dutch Gastric Cancer Study Group, involving 80 Dutch hospitals, conducted a large-scale, RCT in the Netherlands between 1989 and 1993 [10]. In this trial,
996 patients were centrally randomized; 711 patients (380 in the D1 group and 331 in the D2 group) underwent the allocated treatment with curative intent, and 285 patients required palliative treatment. D2 patients had higher postoperative mortality $(10 \%$ vs $4 \%$ for D1; $P=0.004)$; they also had significantly more complications ( $43 \%$ vs $25 \%$ for D1; $P<0.001$ ), which led to a significantly prolonged hospital stay for patients with a D2 dissection. Overall 5-year survival rates were similar in the D1 and D2 groups (45\% for D1 and 47\% for D2). The hazard ratio (HR) comparing the risk of death within 5 years after D2 surgery with that within 5 years after D1 surgery was 1.00 (95\% confidence interval [95\% CI], 0.82-1.22). At a median follow-up of 11 years, $68 \%$ of the patients were deceased, $35 \%$ without and $65 \%$ with recurrent disease. At 11 years, survival rates were $30 \%$ for $\mathrm{D} 1$ and $35 \%$ for D2 $(P=0.53)$, with a risk of relapse of $70 \%$ for D1 and $65 \%$ for D2 $(P=0.43)$ [16]. Interestingly, when hospital deaths were excluded, survival rates were $32 \%$ for D1 $(n=365)$ and $39 \%$ for D2 $(n=299, P=0.10)$, and the relapse risk of these patients $(n=664)$ was in favor of the D2 dissection group $(P=0.07)$. Furthermore, in the subset analysis, 
Table 1. Major randomized controlled trials comparing D1 with D2/D3

\begin{tabular}{|c|c|c|c|c|c|}
\hline Study & Intervention & Patients & Postoperative morbidity & Postoperative mortality & 5-Year survival \\
\hline $\begin{array}{l}\text { Dutch trial } \\
(1989-1993) \\
{[10,15-17]}\end{array}$ & $\begin{array}{l}\text { D1 } \\
\text { D2 }\end{array}$ & $\begin{array}{l}380 \\
331\end{array}$ & $\begin{array}{c}25 \% \\
43 \% \\
(P<0.001)\end{array}$ & $\begin{array}{c}4 \% \\
10 \% \\
(P=0.004)\end{array}$ & $\begin{array}{c}45 \% \\
47 \% \\
\text { HR } 1.00 \\
(95 \% \text { CI, } 0.82-1.22)\end{array}$ \\
\hline $\begin{array}{l}\text { MRC trial } \\
(1987-1994) \\
{[11,18]}\end{array}$ & $\begin{array}{l}\text { D1 } \\
\text { D2 }\end{array}$ & $\begin{array}{l}200 \\
200\end{array}$ & $\begin{array}{c}28 \% \\
46 \% \\
(P<0.001)\end{array}$ & $\begin{array}{c}6.5 \% \\
13 \% \\
(P=0.04)\end{array}$ & $\begin{array}{c}35 \% \\
33 \% \\
\text { HR } 1.10 \\
(95 \% \text { CI, 0.87-1.39) }\end{array}$ \\
\hline $\begin{array}{l}\text { IGCSG trial } \\
(1999-2002) \\
{[15]}\end{array}$ & $\begin{array}{l}\text { D1 } \\
\text { D2 }\end{array}$ & $\begin{array}{l}76 \\
86\end{array}$ & $\begin{array}{c}10.5 \% \\
16.3 \% \\
(P<0.29)\end{array}$ & $\begin{array}{l}0 \% \\
1.3 \% \\
\text { (N.S) }\end{array}$ & Under analysis \\
\hline $\begin{array}{l}\text { Taiwanese trial } \\
{[14,19]}\end{array}$ & $\begin{array}{l}\text { D1 } \\
\text { D3 }\end{array}$ & $\begin{array}{l}110 \\
111\end{array}$ & $\begin{array}{c}7.3 \% \\
17.1 \% \\
(P=0.012)\end{array}$ & $\begin{array}{l}0 \% \\
0 \%\end{array}$ & $\begin{array}{c}53.6 \% \\
59.5 \% \\
\text { HR } 0.49 \\
(95 \% \text { CI, } 0.32-0.77)\end{array}$ \\
\hline
\end{tabular}

MRC, Medical Research Council; IGCSG, Italian Gastric Cancer Study Group; HR, hazard ratio; 95\% CI, 95\% confidence interval

when hospital deaths were excluded, there was a significant survival and relapse advantage for patients with International Union Against Cancer (UICC) $\mathrm{pN} 2$ disease who had a D2 dissection $(P=0.01)$. Other stages showed no significant differences (N0 $P=0.42$; N1 $P=$ $0.31 ;$ N3 $P=0.24$ ).

This trial showed an extremely high hospital mortality after D2 dissection [17]. Such a high mortality was caused by a very low hospital volume. Lack of experience in dealing with major surgical complications after D2 dissection; namely, anastomotic leakage, pancreatic fistula, and intraabdominal abscess, led to the high mortality. Low-quality surgery with high mortality immediately after operation could explain why D2 dissection was not found to be beneficial. Furthermore, in this study, there was a high rate of protocol violations in terms of lymph node dissection [18]. If lymph nodes were harvested from stations that were not supposed to be included according to the protocol, this was called contamination. If lymph nodes were not harvested from stations that should have been harvested, this was called noncompliance. Contamination occurred in $6 \%$ of the D1 dissection group, and noncompliance occurred in $51 \%$ of the D2 group. Contamination in the D1 dissection group and noncompliance in the D2 group could have led to the small difference between the trial arms.

\section{Medical Research Council Gastric Cancer Surgical Group Trial}

In 1986, the Medical Research Council of Great Britain initiated a nationwide, multi-institutional, RCT comparing D1 dissection with D2 dissection in that country [11].

Central randomization followed a staging laparotomy. Of 737 patients with histologically proven gastric adeno- carcinoma registered, 337 patients were ineligible by staging laparotomy because of advanced disease. Thus, 400 patients were randomized, with 200 patients receiving D1 dissection and 200 patients receiving D2 dissection. Postoperative mortality was significantly higher in the D2 group $(13 \%)$ than in the D1 group $(6.5 \% ; P=$ $0.04)$ [19]. Postoperative complications were also significantly higher in the D2 group (46\%) than in the D1 group (28\%; $P<0.001)$, with the most frequent complications being anastomotic leakage ( $26 \%$ for D2 vs $11 \%$ for D1; $P<0.015)$, cardiac complications ( $8 \%$ for $\mathrm{D} 2$ vs $2 \%$ for D1; no significant difference [NS]), and respiratory complications ( $8 \%$ vs $5 \%$ for D1; NS). In this trial, many surgeons thought that D2 distal gastrectomy included splenectomy, and splenectomy was carried out in many distal gastrectomy cases. Pancreatico-splenectomy was carried out in $56 \%$ of patients allocated to the D2 group and $4 \%$ of the D1 group. This was based on a misunderstanding of the definition of D2 gastrectomy by the JGCA. In Japan, splenectomy is included in D2 dissection only when a total gastrectomy is carried out. Together with thorough lymph node dissection of the lesser curvature, splenectomy causes serious ischemia of the remnant stomach, necrosis of the remnant stomach, or anastomotic leakage. Hospital death in the D2 dissection group was $13 \%$; such a high mortality is no longer accepted for any cancer surgery. In fact, there was no difference in 5 -year survival between the two arms (33\% vs 35\% for D1; HR, 1.10; 95\% CI, 0.87-1.39).

\section{Taiwanese trial}

This study was a single-institutional trial that was carried out between 1993 and 1999. This is the only trial that showed a statistically significant survival benefit of D3 
over D1 gastrectomy [14, 20]. Of 221 patients, 110 patients were randomly assigned to D1 surgery and 111 patients were randomly assigned to D3 surgery between 1993 and 1999. Overall 5-year survival was significantly higher in patients assigned to D3 surgery than in those assigned to D1 surgery ( $59.5 \%$ vs $53.6 \% ; P=0.041)$. The HR comparing the risk of death within 5 years after D3 with that within 5 years after D1 surgery was $0.49(95 \%$ CI, 0.32-0.77). Overall, 215 patients who had R0 resection had recurrence at 5 years $(50.6 \%$ for D1 surgery and $40.3 \%$ for D3 surgery; $P=0.197)$. Five-year diseasespecific survival was significantly higher in patients assigned to D3 surgery than in those assigned to D1 surgery $(64.9 \%$ vs $58.5 \% ; P=0.044 ; \mathrm{HR}, 0.69)$.

\section{Small-scale RCT in South Africa}

Between 1982 and 1986, a small-scale RCT was performed in South Africa, involving 43 patients who were randomized to D1 or D2 resection [12]. Although there were no hospital deaths, D2 gastrectomy was associated with longer operating time, more blood loss, longer hospital stays, and a higher reoperation rate, but there was no detailed analysis of complications. There was no survival difference at a median follow-up of 3.1 years.

\section{Small-scale RCT in Hong Kong}

Between 1987 and 1991, another RCT was conducted in Hong Kong [13]. This study randomized 55 patients to either D1 or D3 gastrectomy; D3 patients had longer operative times, greater transfusion needs, longer hospital stays, and more subphrenic abscesses than D1 patients. There was no detailed statistical analysis of postoperative complications in the D1 group. One patient in the D3 group died from operative complications. Overall survival was better in the $\mathrm{D} 1$ group $(P=0.07)$.

It is obvious that the two large-scale RCTs in the Netherlands and the United Kingdom showed the same tendency. The Dutch and MRC studies had extremely high hospital mortality after D2 dissection, 10\% and $13 \%$, respectively. Such a high mortality negated the survival benefits of D2 dissection. The critics of these trials have suggested that there was inadequate pretrial training of the surgeons; in particular, their lack of experience in treating major surgical complications led to the high hospital mortality. Morbidity and mortality are significantly related to hospital volume [21]. The learning curve for a D2 gastrectomy may be up to 25 cases $[22,23]$. The number of patients per hospital per year was 1.0 in the Dutch trial and 1.5 in the MRC trial. After these two trials with miserable short-term results, the Italian Gastric Cancer Study Group (IGCSG) performed a phase II study between 1994 and 1996 to assess the safety of D2 gastrectomy [24]. In this study, postoperative complications were seen in $20.9 \%$ of patients, with only $3.1 \%$ mortality. This trial was carried out in only nine hospitals, and only 18 surgeons participated in the trial. They avoided splenectomy in distal gastrectomy and the routine use of distal pancreatectomy in total gastrectomy. They also performed a phase III trial comparing D1 gastrectomy to D2 gastrectomy [15]. In that phase III trial, postoperative morbidity was $16.3 \%$ in $\mathrm{D} 2$ gastrectomy and $10.5 \%$ in $\mathrm{D} 1$ gastrectomy, and postoperative mortality was $1.3 \%$ after D1 but $0 \%$ after D2 gastrectomy. There were no significant differences in the postoperative morbidity and mortality between the two groups. Therefore, D2 gastrectomy was regarded as a safe treatment for gastric cancer in experienced centers. The lack of experience with the D2 gastrectomy and with postoperative care led to a poor outcome in patients with D2 gastrectomy in the Dutch and MRC trials. The results of the phase III study by the IGCSG are awaited.

\section{D2 versus D3 trial}

In Japan, D2 gastrectomy is regarded as a safe operation, and D2 gastrectomy is a common practice in ordinary general hospitals. Therefore, in Japan, conducting a D1 versus D2 trial was considered unethical. Japanese surgeons first introduced the D2 gastrectomy in the 1960s [25]. Since the 1980s, gastrectomy with more radical extended lymphadenectomy (D3; superextended lymphadenectomy) has been practiced at many specialized centers in Japan [26-29]. In advanced gastric cancer, the incidence of microscopic metastases in the paraaortic nodes was $6 \%$ to $33 \%$ [29]. The 5-year survival for these patients has reached $12 \%$ to $23 \%$ after gastrectomy with super-extended lymph node dissection. In Japan, between 1995 and 2001, the Japanese Clinical Oncology Group (JCOG) conducted a randomized trial comparing D2 gastrectomy alone with D2 plus paraaortic node dissection (PAND) [30]. A total of 523 patients with curable $\mathrm{T} 2 \mathrm{~b}, \mathrm{~T} 3$, or T4 gastric cancer were randomly assigned to D2 lymphadenectomy alone (263 patients) or to D2 plus PAND (260 patients). The overall operative morbidity rate was $24.5 \%$. The morbidity for the D2+PAND group was higher than that for the D2 alone group ( $28.1 \%$ and $20.9 \%$, respectively), but there was no significant difference between the groups $(P=0.067)$ [31]. There were four hospital deaths $(0.8 \%), 2$ patients in each group $(P=0.99)$. The 5 -year overall survival rates after D2 plus PAND were not significantly better than those after D2 alone (D2, 69.2\% and D2+PAND, 70.3\%; HR, 1.03; 95\% CI, 0.771.37). The two survival curves were almost overlapping, while D2 plus PAND showed longer operation time and more blood loss than D2. This study concluded that 
prophylactic D2+PAND should not be carried out for curable gastric cancer.

Another phase III trial compared D2 to D2 plus PAND in Poland [32]. Of 275 patients enrolled, 141 patients were allocated to D2 alone and 134 patients were allocated to D2+PAND. The morbidity rates were $27.7 \%$ for D2 and $21.6 \%$ for D2 plus PAND $(P=0.248)$. The postoperative mortality rates were $4.9 \%$ for D2 and $2.2 \%$ for D2 plus PAND $(P=0.375)$. In this study, PAND did not result in increased morbidity and mortality, but the survival benefits remain to be analyzed.

In East Asia, another RCT comparing D2 with D2 plus PAND was carried out between 1995 and 2002 [33, 34]. A total of 269 patients were randomized, with 135 patients receiving D2 dissection and 134 patients receiving D2 plus PAND dissection. Postoperative morbidity was significantly higher in the D2 plus PAND group $(39 \%)$ than in the D2 group $(26 \% ; P=0.023)$. Hospital mortality was $0.7 \%$ in the D2 group and $3.7 \%$ in the D2 plus PAND group $(P=0.12)$. The overall 5-year survival was $52.6 \%$ for the $\mathrm{D} 2$ group and $55.4 \%$ for the $\mathrm{D} 2$ plus PAND group; there was no survival benefit of PAND over standard D2 lymphadenectomy $(P=0.801)$.

These three trials demonstrated that both D2 and D3 gastrectomy are safe treatments. However, at the present time, D3 dissection should not be performed for curable gastric cancer, because evidence of survival benefits is lacking (Table 2).

\section{Should splenectomy or pancreatico-splenectomy be carried out routinely in the treatment of cancer of the upper third of the stomach?}

\section{Pancreatico-splenectomy should not be carried out routinely}

No RCT has proven the survival benefits of pancreatico-splenectomy (PS) with total gastrectomy. In Japan, PS for lymph node dissection around the splenic artery and splenic hilum had been widely performed $[35,36]$, because this has been proposed as a radical procedure for complete removal of metastatic lymph nodes along the splenic artery. However, a Japanese retrospective analysis showed no survival benefit from these procedures $[37,38]$, and PS was proven to be dangerous in RCTs $[16,18]$. In the MRC trial, PS was performed in $56 \%$ of patients allocated to the D2 gastrectomy group, and PS had a marked adverse effect on both morbidity (58\% for D2+PS and $30 \%$ for D2 without PS; $P<0.001)$ and mortality $(16 \%$ for D2+PS and $9 \%$ for D2 without PS; $P=0.01$ ). In the Dutch trial, PS was performed for 108 patients in the D1 and D2 groups, and the morbidity and mortality rates were $40 \%$ and $12 \%$, respectively (relative risk, $3.43 ; 95 \% \mathrm{CI}$, 2.49-4.72) [15]. In the JCOG 9501 trial, PS was identified as a significant independent risk factor for complications [31]. PS was performed in only 22 of the 523 registered patients, and complications were identified in 13 patients $(59 \%)$. There is no doubt that PS results in a high incidence of complications. In the Dutch trial, in a subgroup analysis of patients who did not have a PS $(n=603)$, morbidity and mortality were significantly higher in the D2 group, but the 11-year survival rate was significantly better in the D2 group than in the D1 group ( $31 \%$ vs $42 \% ; P=0.02$ ) [39]. There appears to be a survival benefit of D2 gastrectomy if procedures that increase morbidity and mortality, such as PS, can be avoided.

Therefore, PS is considered to be beneficial only when there is direct tumor invasion to the pancreas.

\section{Is splenectomy indeed effective treatment?}

In the JCOG 9501 trial and the IGCSG phase III trial, a low incidence of hospital deaths was achieved because a pancreas-preserving splenectomy was generally used $[15,31]$. Pancreas-preserving splenectomy is considered to be a safe procedure that does not decrease surgical

Table 2. Randomized controlled trials comparing D2 with D2 + PAND

\begin{tabular}{|c|c|c|c|c|c|}
\hline Study & Intervention & Patients & Postoperative morbidity & Postoperative mortality & 5-Year survival \\
\hline $\begin{array}{l}\text { JCOG trial } \\
(1995-2001) \\
{[30,31]}\end{array}$ & $\begin{array}{c}\mathrm{D} 2 \\
\mathrm{D} 2+\mathrm{PAND}\end{array}$ & $\begin{array}{l}263 \\
260\end{array}$ & $\begin{array}{c}20.9 \% \\
28.1 \% \\
(P=0.067)\end{array}$ & $\begin{array}{c}0.8 \% \\
0.8 \% \\
(P=0.99)\end{array}$ & $\begin{array}{c}69.2 \% \\
70.3 \% \\
\text { HR } 1.03 \\
(95 \% \text { CI, } 0.77-1.37)\end{array}$ \\
\hline $\begin{array}{l}\text { Polish trial } \\
(1999-2003) \\
{[32]}\end{array}$ & $\begin{array}{c}\mathrm{D} 2 \\
\mathrm{D} 2+\mathrm{PAND}\end{array}$ & $\begin{array}{l}141 \\
134\end{array}$ & $\begin{array}{c}27.7 \% \\
21.6 \% \\
(P=0.248)\end{array}$ & $\begin{array}{c}4.9 \% \\
2.2 \% \\
(P=0.37)\end{array}$ & Under analysis \\
\hline $\begin{array}{l}\text { East Asian trial } \\
(1995-2002) \\
{[33,34]}\end{array}$ & $\begin{array}{c}\mathrm{D} 2 \\
\mathrm{D} 2+\mathrm{PAND}\end{array}$ & $\begin{array}{l}135 \\
134\end{array}$ & $\begin{array}{c}26 \% \\
39 \% \\
(P=0.023)\end{array}$ & $\begin{array}{c}0.7 \% \\
3.7 \% \\
(P=0.107)\end{array}$ & $\begin{array}{c}52.6 \% \\
55.4 \% \\
(P=0.801)\end{array}$ \\
\hline
\end{tabular}

JCOG, Japan Clinical Oncology Group; PAND, paraaortic node dissection; HR, hazard ratio; 95\% CI, 95\% confidence interval 
Table 3. Randomized controlled trials related to splenectomy for gastric cancer

\begin{tabular}{|c|c|c|c|c|c|c|c|c|}
\hline \multirow[b]{2}{*}{ Study } & \multirow[b]{2}{*}{ Intervention } & \multirow[b]{2}{*}{ Patients } & \multicolumn{4}{|c|}{ Postoperative morbidity } & \multirow[b]{2}{*}{$\begin{array}{c}\text { Postoperative } \\
\text { mortality }\end{array}$} & \multirow[b]{2}{*}{$\begin{array}{l}\text { 5-Year } \\
\text { survival }\end{array}$} \\
\hline & & & Any & Fever $>38^{\circ} \mathrm{C}$ & Pulmonary & $\begin{array}{c}\text { Subphrenic } \\
\text { abscess }\end{array}$ & & \\
\hline $\begin{array}{l}\text { Chilean trial } \\
(1985-1992) \\
{[47]}\end{array}$ & $\begin{array}{c}\text { TG } \\
\mathrm{TG}+\mathrm{S}\end{array}$ & $\begin{array}{l}97 \\
90\end{array}$ & Not stated & $\begin{array}{c}39 \% \\
50 \% \\
(P<0.04)\end{array}$ & $\begin{array}{c}24 \% \\
39 \% \\
(P<0.008)\end{array}$ & $\begin{array}{c}4 \% \\
11 \% \\
(P<0.05)\end{array}$ & $\begin{array}{c}3.1 \% \\
4.4 \% \\
(P>0.7)\end{array}$ & $\begin{array}{l}36 \% \\
42 \%\end{array}$ \\
\hline $\begin{array}{l}\text { Korean trial } \\
(1995-1999) \\
{[48]}\end{array}$ & $\begin{array}{c}\mathrm{TG} \\
\mathrm{TG}+\mathrm{S}\end{array}$ & $\begin{array}{l}103 \\
104\end{array}$ & $\begin{array}{c}8.7 \% \\
15.4 \% \\
(P=0.142)\end{array}$ & Not stated & Not stated & Not stated & $\begin{array}{c}1.0 \% \\
1.0 \% \\
(P=1.000)\end{array}$ & $\begin{array}{c}48.8 \% \\
54.8 \% \\
(P=0.503)\end{array}$ \\
\hline
\end{tabular}

TG, total gastrectomy; $\mathrm{TG}+\mathrm{S}$, total gastrectomy with splenectomy

curability [40-42]. However, it is not known whether splenectomy contributes to survival.

From the Japanese experience with splenectomy, the incidence of hilar nodal metastasis ranged from $0-2 \%$ for distal and middle-third gastric cancer, to $15 \%$ for proximal-third tumors, and $21 \%$ for tumors that infiltrate the entire stomach. Based on retrospective data, hilar nodal metastasis was not found in EGC [43-46]. These data suggested that splenectomy was crucial for the curative resection of proximal advanced gastric cancer and might improve the prognosis.

Two RCTs compared the effectiveness and safety of gastrectomy with splenectomy to gastrectomy alone in patients with gastric cancer (Table 3). One of these RCTs was carried out in Chile [47], and the other was carried out in Korea [48]. Both studies were performed in single institutions. In Chile, between 1985 and 1992, 187 patients with gastric cancer, including early-stage cases, were randomized. However, this study did not state how the patients were randomized. Total gastrectomy was performed for all patients. The frequency of septic complications, including postoperative fever higher than $38^{\circ} \mathrm{C}$, pulmonary complications, and subphrenic abscess, was significantly higher in the splenectomy group than in the gastrectomy-alone group (fever, $50 \%$ vs $39 \% ; P<0.04$; pulmonary, $39 \%$ vs $24 \%, P<$ 0.008 ; subphrenic abscess, $11 \%$ vs $4 \%, P<0.05$, respectively). There was no significant difference between the groups in the hospital mortality rate $(4.4 \%$ for splenectomy vs $3.1 \%$ for gastrectomy alone; $P>0.7)$. In this study, the survival statistics excluded the operative mortality rate. The 5 -year survival rates were $42 \%$ for splenectomy and $36 \%$ for gastrectomy alone; there was no significant difference between the groups $(P>0.5)$. In subgroup analysis, there was no survival benefit for stage II, IIIA, and IIIB cancer.

In the other trial, carried out in Korea between 1995 and 1999, 207 patients with gastric cancer were randomized to either total gastrectomy or total gastrectomy plus splenectomy for lymph node dissection at the splenic hilum and along the splenic artery. Overall, 103 patients had the spleen-preserving procedure, and 104 had splenectomy. Postoperative morbidity was $8.7 \%$ in the spleen-preserving group and $15.4 \%$ in the splenectomy group, but there was no significant difference between the groups $(P=0.142)$. One patient $(1.0 \%)$ in the spleen-preserving group and 2 patients $(1.9 \%)$ in the splenectomy group died from postoperative complications, but this difference was not significant $(P=$ 1.000). The incidence of metastasis at the splenic hilum and along the splenic artery was $10.6 \%$ and $17.3 \%$, respectively. The 5-year survival rate was $48.8 \%$ for patients in the spleen-preserving group and $54.8 \%$ in the splenectomy group; there was no significant difference $(P=0.503)$. The 5-year survival rate of patients with lymph node metastasis at the splenic hilum was $0 \%$, with or without splenectomy. In the subgroup with lymph node metastasis along the splenic artery, the 5 -year survival rate was $20.0 \%$ in the spleen-preserving group and $23.4 \%$ in the splenectomy group $(P=0.753)$. Therefore, these results did not support the use of prophylactic splenectomy to remove macroscopically negative lymph nodes near the spleen in patients undergoing total gastrectomy for proximal gastric cancer.

In Japan, an RCT to evaluate splenectomy for upperthird advanced gastric cancer is ongoing [49]. This trial includes the evaluation of long-term survival, postoperative morbidity, mortality, and quality of life. Registration of about 500 patients has been completed, and the results of this study are awaited.

\section{Mediastinal lymph node dissection for gastric cancer with esophageal invasion}

Siewert and Stein [50] developed a now widely used classification of carcinomas involving the stomach and esophagus into three types: adenocarcinoma of the distal esophagus, which may infiltrate the esophagogastric junction from above (type I); true cardia carcinoma arising from the esophagogastric junction (type II); and subcardial gastric carcinoma that infiltrates the esopha- 
gogastric junction and distal esophagus from below (type III). According to the Siewert classification, gastric cancer with esophageal invasion is classified as type II or type III. In Japan, an RCT comparing left thoraco-abdominal esophagogastrectomy (LTE) versus transhiatal esophagogastrectomy (THE) for Siewert type II and III tumors with esophageal invasion of $3 \mathrm{~cm}$ or less was carried out [51] (Table 4). Between 1995 and 2003, 167 patients were enrolled and randomly assigned to LTE $(n=85)$ or THE $(n=82) ; 95$ tumors were classified as Siewert type II and 63 as type III. Nine tumors could not be classified using the Siewert classification because they were large or because data were missing. The postoperative morbidity rate was $49 \%$ in the LTE group and $34 \%$ in the THE group $(P=0.06)$. Three patients in the LTE group died in hospital, but there was no mortality in the THE group $(P=0.25)$; 5-year survival was $37.9 \%$ in the LTE group and $52.3 \%$ in the THE group $(P=0.93)$. The HR of death for LTE compared to THE was 1.30 (95\% CI, 0.83-2.02; $P=0.92$ ). This trial concluded that LTE could not be justified to treat cancer of the cardia or subcardia because LTE did not improve survival over THE, and it increased morbidity.

Another RCT that compared THE with transthoracic esophagogastrectomy (TTE) for adenocarcinoma of the esophagogastric junction or esophagus was performed in The Netherlands between 1994 and 2000 [52, 53]. In this trial, 220 patients with Siewert type I and type II tumors were enrolled; 106 patients were assigned to THE, and 114 were assigned to TTE. THE was associated with fewer pulmonary complications, a shorter duration of mechanical ventilation, and shorter stays in the intensive care unit (ICU) and in the hospital. Two patients in the THE group and 5 patients in the TTE group died in hospital; there difference in hospital mortality between the two groups was not significant $(P=$ $0.45)$. The 5-year survival rate was $34 \%$ for the THE group and $36 \%$ for the TTE group ( $P=0.71)$. According to the Siewert classification, 90 patients (43 patients in THE group and 47 patients in the TTE group) were classified as having type I tumors, and 115 patients (52 patients in the THE group and 63 patients in the TTE group) were classified as having type II tumors. The difference in overall 5-year survival was as large as $14 \%$ (37\% for THE vs $51 \%$ for TTE; $P=0.33$ ) for type $\mathrm{I}$ tumors, while it was negligible for type II tumors (31\% for THE and $27 \%$ for TTE; 5-year survival difference, $-4 \% ; P=0.81)$. The results of this study strongly suggested that thorough mediastinal dissection via right thoracotomy is needed for type I tumors but not for type II tumors, although there was no significant difference in survival.

In view of the results of these two trials, the transhiatal approach is regarded as the standard treatment for patients with Siewert type II and III tumors.

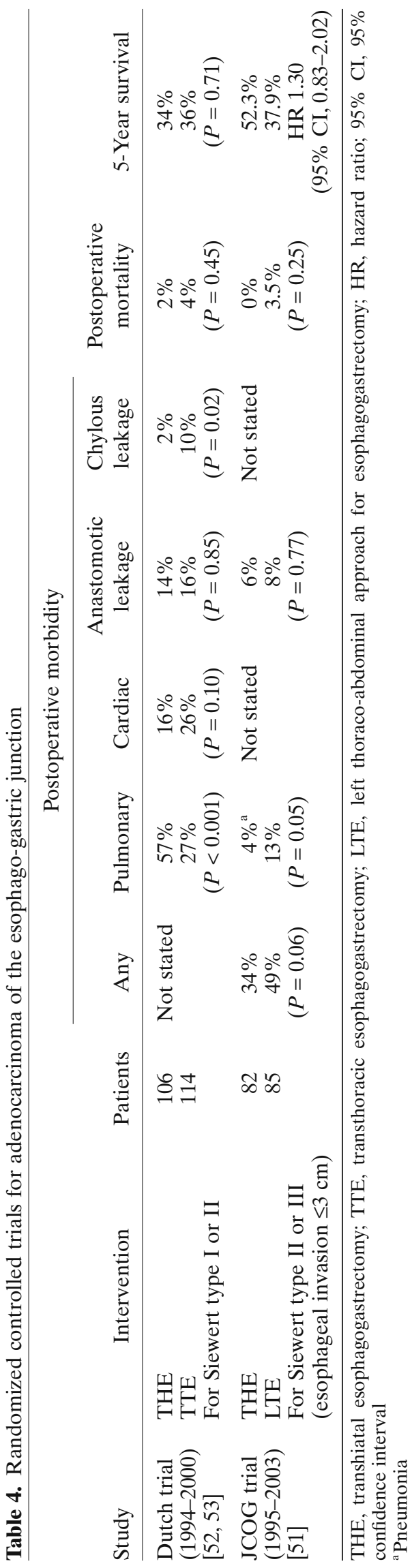


Table 5. Japanese guidelines for surgical treatment (curative intention) by stage

\begin{tabular}{|c|c|c|c|c|}
\hline & N0 & N1 & $\mathrm{N} 2$ & $\mathrm{~N} 3$ \\
\hline \multirow[t]{4}{*}{$\mathrm{T} 1$ (M) } & IA & IB & II & IV \\
\hline & A) ER (differentiated type, & A) $\operatorname{MGB}(\leq 2 \mathrm{~cm})$ & D2 & D3 \\
\hline & $\leq 2 \mathrm{~cm}, \mathrm{UL}(-))$ & B) D2 $(>2 \mathrm{~cm})$ & & \\
\hline & B) MGA (remainder) & & & \\
\hline \multirow{4}{*}{$\mathrm{T} 1$ (SM) } & IA & IB & II & IV \\
\hline & A) MGA (differentiated & A) $\operatorname{MGB}(\leq 2 \mathrm{~cm})$ & D2 & D3 \\
\hline & type, $\leq 1.5 \mathrm{~cm})$ & B) D2 $(>2 \mathrm{~cm})$ & & \\
\hline & B) MGB (remainder) & & & \\
\hline \multirow[t]{2}{*}{$\mathrm{T} 2$} & IB & II & IIIA & IV \\
\hline & D2 & D2 & D2 & D3 \\
\hline \multirow[t]{2}{*}{$\mathrm{T} 3$} & II & IIIA & IIIB & IV \\
\hline & D2 & D2 & D2 & D3 \\
\hline \multirow[t]{2}{*}{$\mathrm{T} 4$} & IIIA & IIIB & IV & IV \\
\hline & $\begin{array}{l}\text { D2 with combined } \\
\text { resection }\end{array}$ & $\begin{array}{l}\text { D2 with combined } \\
\text { resection }\end{array}$ & $\begin{array}{l}\text { D2 with combined } \\
\text { resection }\end{array}$ & $\begin{array}{l}\text { D3 with combined } \\
\text { resection }\end{array}$ \\
\hline
\end{tabular}

ER, endoscopic resection; MGA, modified gastrectomy A; MGB, modified gastrectomy B; UL, with ulcerated lesion

\section{The treatment of early gastric cancer}

There is a major difference in the proportion of EGCs in Japan and Korea compared to the rest of the world. EGCs now account for nearly $50 \%$ of all gastric cancers treated at major institutions in Japan and Korea [54, 55]. However, in Western countries, the frequency of EGC was only $10 \%-20 \%[56,57]$. Therefore, the majority of reports on EGC have been published from Japan. However, there are a few reports of RCTs dealing with the extent of lymphadenectomy for EGC.

The JGCA issued a set of treatment guidelines to help standardize treatment (Table 5) [2]. In Japan, resection of at least two-thirds of the stomach with D2 lymphadenectomy has been conventional surgical treatment for gastric cancer, including EGC, though conservative treatments such as endoscopic mucosal resection or function-preserving limited gastrectomy for EGC have recently been performed $[58,59]$.

\section{The indications for endoscopic resection}

Endoscopic resection is comparable in many respects to surgical therapy, with the advantages of being less invasive and more economical. The extremely low incidence of lymph node involvement in certain stages of EGC means that cure can be accomplished by such local treatment. Therefore, endoscopic resection is indicated for EGCs without lymph node metastasis. According to the guidelines, the accepted indications for endoscopic resection are: (1) well-differentiated elevated cancers less than $2 \mathrm{~cm}$ in diameter; and (2) small $(\leq 1 \mathrm{~cm})$ depressed lesions without ulceration. In addition, these lesions must be moderately or well-differentiated cancers confined to the mucosa and have no lymphatic or vascular involvement. These criteria for node-negative gastric cancer were defined using a large retrospective database of more than 5000 EGC patients who underwent gastrectomy with D2 lymphadenectomy [60]. The guidelines show the extended indications for which endoscopic resection may be appropriate, and these indications include: differentiated-type mucosal cancer without ulceration greater than $2 \mathrm{~cm}$ in diameter; differentiated-type mucosal cancer with ulceration up to $3 \mathrm{~cm}$ in diameter; undifferentiated-type mucosal cancer without ulceration up to $2 \mathrm{~cm}$ in diameter; and, in the absence of lymphovascular invasion, a tumor not deeper than submucosal level 1 (less than $500 \mu \mathrm{m}$; Fig. 2). However, extending the indications for endoscopic resection remains controversial, because of the lack of supportive clinical evidence. In Japan, a phase II trial of endoscopic resection for EGC, which is clinically diagnosed as belonging to the expanded indications, is ongoing [61].

\section{Surgical treatment for EGC}

According to the Japanese guidelines, modified gastrectomy (MG) should be performed for EGC (Table 6). MG is classified as MG A and MG B according to the extent of resection and lymph node dissection [2]. MG A involves the dissection of group N1 nodes, those in the left gastric artery (station 7), and those in the anterior wall of the common hepatic artery (station 8a). MG $\mathrm{B}$ involves dissection of the lymph nodes in the celiac axis (station 9), in addition to MG A. MG A is indicated for clinically observed mucosal cancers or differentiated-type submucosal cancers smaller than $1.5 \mathrm{~cm}$ in diameter, and MG B is indicated for submucosal cancers and EGCs smaller than $2 \mathrm{~cm}$ with clinical N1 disease. 


\begin{tabular}{|c|c|c|c|c|c|c|c|}
\hline \multirow[b]{3}{*}{ Histology } & \multicolumn{4}{|c|}{ Mucosal cancer } & \multicolumn{3}{|c|}{ Submucosal cancer without UL } \\
\hline & \multicolumn{2}{|c|}{ UL (-) } & \multicolumn{2}{|c|}{ UL (+) } & \multicolumn{2}{|c|}{ SM1 } & \multirow{2}{*}{$\begin{array}{c}\text { SM2 } \\
\text { Any size }\end{array}$} \\
\hline & $\leq 20 \mathrm{~mm}$ & $>20 \mathrm{~mm}$ & $\leq 30 \mathrm{~mm}$ & $>30 \mathrm{~mm}$ & $\leq 30 \mathrm{~mm}$ & $>30 \mathrm{~mm}$ & \\
\hline Differentiated & & & & & & & \\
\hline Undifferentiated & & & & & & & \\
\hline
\end{tabular}

Fig. 2. Japanese guideline criteria for endoscopic resection. Size is shown in mm. Black area, Guideline criteria for endoscopic resection; gray area, criteria for extended endoscopic resection; white area, no indication for endoscopic resection. $U L$, With ulcerated lesion; $S M 1$, submucosal level 1 ( $\leq 500 \mu \mathrm{m}$ from lamina muscularis mucosae); $S M 2$, submucosal level 2 ( $>500 \mu \mathrm{m}$ from lamina muscularis mucosae)

Table 6. Areas of gastric resection and extent of LN dissection

\begin{tabular}{lcc}
\hline Type of gastrectomy & Area of gastric resection & Extent of LN dissection \\
\hline Modified gastrectomy A & $<2 / 3$ & D1 + station 7 \\
Modified gastrectomy B & $<2 / 3$ & D1 + station 7, 8a, 9 \\
Standard & $\geq 2 / 3$ & D2
\end{tabular}

LN, lymph node

${ }^{a}$ In lower-third cancer, station 8 a nodes should be dissected

In cases of EGC in which endoscopic resection is not appropriate, though there is a low risk of lymph node metastasis, MG A is performed. Basically, MG A is indicated for apparent intramucosal cancers with no lymph node involvement in which endoscopic resection is not appropriate, or for differentiated submucosal cancers of about $1.5 \mathrm{~cm}$ diameter that are found to be node-negative during operation. MG B can be used for cases of apparent submucosal cancers that are diagnosed during the operation as being node-negative and it can be used for patients with tumors of less than $2 \mathrm{~cm}$ who are suspected of having metastasis to the group N1 lymph nodes for which dissection would result in cure. These criteria were established on the basis of retrospective data [8, 62-68]. However, pre- or intraoperative diagnosis is not always accurate, so it is inevitable that over-diagnosis occurs when surgeons decide whether limited resection is feasible.

\section{Limited resection of the stomach for early gastric cancer}

Recently, pylorus-preserving gastrectomy (PPG) or proximal gastrectomy has been performed for EGC when the tumor location is suitable for these limited resections. The purpose of these approaches is to preserve the gastric reservoir, and they have a favorable outcome. However, the extent of lymph node dissection in these approaches is also limited. Therefore, the surgeon must carefully judge whether these limited gastrectomies are appropriate.

\section{Pylorus-preserving gastrectomy}

PPG is currently indicated for EGC in the gastric body $[69,70]$. PPG is a modification of distal gastrectomy, preserving $2-3 \mathrm{~cm}$ of the pyloric cuff, which maintains pyloric ring function. In a retrospective study, the incidences of dumping syndrome, biliary reflux, and gallbladder stone formation were lower, and body weight recovery was better following PPG than after Billroth I reconstruction [71-75]. In a prospective randomized trial, only dumping syndrome was reduced [76].

The indication for PPG is early cancer located in the middle third of the stomach without lymph node metastasis, excluding patients who are candidates for endoscopic resection. In PPG, all regional lymph nodes, except for the suprapyloric nodes, should be dissected, as in the standard D2 gastrectomy. It is unnecessary to dissect suprapyloric nodes (station 5) routinely, because metastases to suprapyloric nodes are extremely uncommon from cancer in the middle third of the stomach $[69,77,78]$.

For preserving pyloric function, it is necessary that $2-3 \mathrm{~cm}$ of the pyloric cuff is preserved, so PPG is indicated for tumors more than $4 \mathrm{~cm}$ from the pyloric ring to maintain the distal margin.

\section{Proximal gastrectomy}

Proximal gastrectomy is currently indicated for EGC only when at least half of the stomach can be preserved to maintain both the curability of the operation and the functional capacity of the remnant stomach [79]. Splenectomy is not performed. Therefore, nodes of the 
splenic hilum (station 10) and the distal splenic nodes (station 11d) are not dissected, and the dissection of the distal lesser curvature nodes (station 3 ) is complete because of the preservation of the distal stomach. There are retrospective data that support this procedure for EGC in the upper third of the stomach. There were no positive nodes along the right gastroepiploic vessels (station 4d), suprapyloric nodes (station 5), infrapyloric nodes (station 6), nodes in the splenic hilum (station 10 ), or nodes along the distal splenic artery (station 11d) in 258 EGCs of the upper third of the stomach in which total gastrectomy + D2 lymphadenectomy was performed [79]. Prospective studies have demonstrated that proximal gastrectomy for early upper-third gastric cancer can be performed safely with an excellent cure rate [80-82]. Some studies have shown improvement of postoperative absorption and body weight recovery to be better after proximal than after total gastrectomy $[83,84]$.

\section{Future perspectives}

There is no doubt that gastrectomy with regional lymph node dissection is the only treatment modality for advanced gastric cancer. In Japan and Korea, gastrectomy with D2 lymphadenectomy is the gold standard of treatment for advanced gastric cancer. However, several studies have revealed that more extended resection than D2 surgery has no impact on survival. In order to improve locoregional control of gastric cancer, multimodal treatment involving chemotherapy or radiotherapy in addition to surgery is thought to be a promising treatment strategy. Survival benefits from adjuvant chemotherapy or chemoradiotherapy have been demonstrated in some studies [85-87]. Moreover, molecular targeting agents, such as bevacizumab, cetuximab, and panitumumab, have been introduced to clinical practice for the treatment of gastric cancer [88, 89]. To improve the survival of patients with advanced gastric cancer it is necessary to use these active new agents effectively in addition to conventional cytotoxic agents before or after surgery.

On the other hand, for EGC, it is important to clarify the indications for limited resection, including endoscopic resection. The extent of the indications for endoscopic resection should be made clear, and for patients with EGC in whom endoscopic resection is not indicated, sentinel node navigation surgery might be considered. Sentinel node navigation surgery might be able to identify clinically undetectable lymph node metastases and provide essential information for performing individualized selective lymphadenectomy [90-92].

\section{References}

1. Pisani P, Parkin DM, Bray F, Ferlay J. Estimates of the worldwide mortality from 25 cancers in 1990. Int J Cancer 1999;83:1829.

2. Nakajima T. Gastric cancer treatment guidelines in Japan. Gastric Cancer 2002;5:1-5.

3. Lee HJ, Yang HK, Ahn YO. Gastric cancer in Korea. Gastric Cancer 2002;5:177-82.

4. McCulloch P, Niita ME, Kazi H, Gama-Rodrigues JJ. Gastrectomy with extended lymphadenectomy for primary treatment of gastric cancer. Br J Surg 2005;92:5-13.

5. Gunderson LL, Sosin H. Adenocarcinoma of the stomach: areas of failure in a re-operation series (second or symptomatic look) clinicopathologic correlation and implications for adjuvant therapy. Int J Radiat Oncol Biol Phys 1982;8:1-11.

6. Sano T, Sasako M, Kinoshita T, Maruyama K. Recurrence of early gastric cancer. Follow-up of 1475 patients and review of Japanese literature. Cancer 1993;72:3174-78.

7. Sue-Ling HM, Johnston D, Martin IG, Dixon MF, Lansdown MR, McMahon MJ, et al. Gastric cancer: a curable disease in Britain. BMJ 1993;307:591-6.

8. Maehara Y, Orita H, Okuyama T, Moriguchi S, Tsujitani S, Korenaga D, et al. Predictors of lymph node metastasis in early gastric cancer. Br J Surg 1992;79:245-7.

9. Japanese Gastric Cancer Association. Japanese classification of gastric carcinoma - 2nd English edition - . Gastric Cancer 1998; 1:10-24.

10. Bonenkamp JJ, Hermans J, Sasako M, van de Velde CJ, Welvaart $\mathrm{K}$, Songun I, et al. Extended lymph-node dissection for gastric cancer. N Engl J Med 1999;340:908-14.

11. Cuschieri A, Weeden S, Fielding J, Bancewicz J, Craven J, Joypaul V, et al. Patient survival after D1 and D2 resections for gastric cancer: long-term results of the MRC randomized surgical trial. Surgical Co-operative Group. Br J Cancer 1999;79: 1522-30.

12. Dent DM, Madden MV, Price SK. Randomized comparison of R1 and R2 gastrectomy for gastric carcinoma. Br J Surg 1988;75:110-2.

13. Robertson CS, Chung SC, Woods SD, Griffin SM, Raimes SA, Lau JT, et al. A prospective randomized trial comparing R1 subtotal gastrectomy with R3 total gastrectomy forantral cancer. Ann Surg 1994;220:176-82.

14. Wu CW, Hsiung CA, Lo SS, Hsieh MC, Chen JH, Li AF, et al. Nodal dissection for patients with gastric cancer: a randomised controlled trial. Lancet Oncol 2006;7:309-15.

15. Degiuli M, Sasako M, Calgaro M, Garino M, Rebecchi F, Mineccia $\mathrm{M}$, et al. Morbidity and mortality after D1 and D2 gastrectomy for cancer: interim analysis of Italian Gastric Cancer Study Group (IGCSG) randomized surgical trial. Eur J Surg Oncol 2004;30: 303-8.

16. Hartgrink HH, van de Velde CJ, Putter H, Bonenkamp JJ, Klein Kranenbarg E, Songun I, et al. Extended lymph node dissection for gastric cancer: who may benefit? Final results of the randomized Dutch gastric cancer group trial. J Clin Oncol 2004; 22:2069-77.

17. Bonenkamp JJ, Songun I, Hermans J, Sasako M, Welvaart K, Plukker JT, et al. Randomised comparison of morbidity after D1 and D2 dissection for gastric cancer in 996 Dutch patients. Lancet 1995;345:745-8.

18. Bunt AM, Hermans J, Boon MC, van de Velde CJ, Sasako M, Fleuren GJ, et al. Evaluation of the extent of lymphadenectomy in a randomized trial of Western- versus Japanese-type surgery in gastric cancer. J Clin Oncol 1994;12:417-22.

19. Cuschieri A, Fayers P, Fielding J, Craven J, Bancewicz J, Joypaul $\mathrm{V}$, et al. Postoperative morbidity and mortality after D1 and D2 resections for gastric cancer: preliminary results of the MRC randomised controlled surgical trial. The Surgical Cooperative Group. Lancet 1996;347:995-9. 
20. Wu CW, Hsiung CA, Lo SS, Hsieh MC, Shia LT, Whang-Peng J. Randomized clinical trial of morbidity after D1 and D3 surgery for gastric cancer. Br J Surg 2004;91:283-7.

21. Sasako M, Saka M, Fukagawa T, Katai H, Sano T. Modern surgery for gastric cancer- Japanese perspective. Scand J Surg 2006;95:232-5.

22. Parikh D, Johnson M, Chagla L, Lowe D, McCulloch P. D2 gastrectomy: lessons from a prospective audit of the learning curve. Br J Surg 1996;83:1595-9.

23. Lee JH, Ryu KW, Lee JH, Park SR, Kim CG, Kook MC, et al. Learning curve for total gastrectomy with $\mathrm{D} 2$ lymph node dissection: cumulative sum analysis for qualified surgery. Ann Surg Oncol 2006;13:1175-81.

24. Degiuli M, Sasako M, Ponti A, Soldati T, Danese F, Calvo F. Morbidity and mortality after D2 gastrectomy for gastric cancer: results of the Italian Gastric Cancer Study Group prospective multicenter surgical study. J Clin Oncol 1998;16:1490-3.

25. Kajitani T. The general rules for the gastric cancer study in surgrey and pathology: Part 1- Clinical classification. Jpn J Surg 1981;11:127-39.

26. Baba M, Hokita S, Natsugoe S, Miyazono T, Shimada M, Nakano $\mathrm{S}$, et al. Paraaortic lymphadenectomy in patients with advanced carcinoma of the upper third of the stomach. Hepatogastroenterology 2000;47:893-6.

27. Kunisaki C, Shimada H, Yamaoka H, Takahashi M, Ookubo K, Akiyama $\mathrm{H}$, et al. Indications for paraaortic lymph node dissection in gastric cancer patients with paraaortic lymph node involvement. Hepatogastroenterology 2000;47:586-9.

28. Isozaki H, Okajima K, Fujii K, Nomura E, Izumi N, Mabuchi H, et al. Effectiveness of paraaortic lymph node dissection for advanced gastric cancer. Hepatogastroenterology 1999;46: 549-54.

29. Takashima S, Kosaka T. Results and controversial issues regarding a para aortic lymph node dissection for advanced gastric cancer. Surg Today 2005;35:425-31.

30. Sasako M, Sano T, Yamamoto S, Kurokawa Y, Nashimoto A, Kurita A, et al. D2 lymphadenectomy alone or with para-aortic nodal dissection for gastric cancer. N Engl J Med 2008; 359:453-62.

31. Sano T, Sasako M, Yamamoto S, Nashimoto A, Kurita A, Hiratsuka M, et al. Gastric cancer surgery: morbidity and mortality results from a prospective randomized controlled trial comparing D2 and extended para-aortic lymphadenectomy-Japan Clinical Oncology Group study 9501. J Clin Oncol 2004; 22:2767-73.

32. Kulig J, Popiela T, Kolodziejczyk P, Sierzega M, Szczepanik A. Standard D2 versus extended D2 (D2+) lymphadenectomy for gastric cancer: an interim safety analysis of a multicenter, randomized, clinical trial. Am J Surg 2007;193:10-5.

33. Yonemura Y, Wu CC, Fukushima N, Honda I, Bandou E, Kawamura T, et al. Operative morbidity and mortality after D2 and D4 extended dissection for advanced gastric cancer: a prospective randomized trial conducted by Asian surgeons. Hepatogastroenterology 2006;53:389-94.

34. Yonemura Y, Wu CC, Fukushima N, Honda I, Bandou E, Kawamura T, et al. Randomized clinical trial of D2 and extended paraaortic lymphadenectomy in patients with gastric cancer. Int J Clin Oncol 2008;13:132-7.

35. Bruschwig A. Pancreato-total gastrectomy and splenectomy for advanced carcinoma of the stomach. Cancer 1948;1:427-30.

36. Noguchi Y, Imada T, Matsumoto A, Coit DG, Brennan MF. Radical surgery for gastric cancer. A review of the Japanese experience. Cancer 1989;64:2053-62.

37. Kitamura K, Nishida S, Ichikawa D, Taniguchi H, Hagiwara A, Yamaguchi T, et al. No survival benefit from combined pancreaticosplenectomy and total gastrectomy for gastric cancer. $\mathrm{Br} \mathrm{J}$ Surg 1999;86:119-22.

38. Kodera Y, Yamamura Y, Shimizu Y, Torii A, Hirai T, Yasui K, et al. Lack of benefit of combined pancreaticosplenectomy in D2 resection for proximal-third gastric carcinoma. World J Surg 1997;21:622-7.

39. Hartgrink HH, van de Velde CJ. Status of extended lymph node dissection: locoregional control is the only way to survive gastric cancer. J Surg Oncol 2005;90:153-65.

40. Maruyama K, Sasako M, Kinoshita T, Sano T, Katai H, Okajima K. Pancreas-preserving total gastrectomy for proximal gastric cancer. World J Surg 1995;19:532-6.

41. Furukawa H, Hiratsuka M, Ishikawa O, Ikeda M, Imamura H, Masutani S, et al. Total gastrectomy with dissection of lymph nodes along the splenic artery: a pancreas-preserving method. Ann Surg Oncol 2000;7:669-73.

42. Doglietto GB, Pacelli F, Caprino P, Bossola M, Di Stasi C. Pancreas-preserving total gastrectomy for gastric cancer. Arch Surg 2000;135:89-94.

43. Yoshino K, Yamada Y, Asanuma F, Aizawa K. Splenectomy in cancer gastrectomy: recommendation of spleen-preserving for early stages. Int Surg 1997;82:150-4.

44. Di Leo A, Marrelli D, Roviello F, Bernini M, Minicozzi A, Giacopuzzi S, et al. Lymph node involvement in gastric cancer for different tumor sites and $\mathrm{T}$ stage: Italian Research Group for Gastric Cancer (IRGGC) experience. J Gastrointest Surg 2007:11:1146-53.

45. Shin SH, Jung H, Choi SH, An JY, Choi MG, Noh JH. Clinical significance of splenic hilar lymph node metastasis in proximal gastric cancer. Ann Surg Oncol 2009;16:1304-9.

46. Ikeguchi M, Kaibara N. Lymph node metastasis at the splenic hilum in proximal gastric cancer. Am Surg 2004;70:645-8.

47. Csendes A, Burdiles P, Rojas J, Braghetto I, Diaz JC, Maluenda F. A prospective randomized study comparing D2 total gastrectomy versus D2 total gastrectomy plus splenectomy in 187 patients with gastric carcinoma. Surgery 2002;131:401-7.

48. Yu W, Choi GS, Chung HY. Randomized clinical trial of splenectomy versus splenic preservation in patients with proximal gastric cancer. Br J Surg 2006;93:559-63.

49. Sano T, Yamamoto S, Sasako M; Japan Clinical Oncology Group Study JCOG 0110-MF. Randomized controlled trial to evaluate splenectomy in total gastrectomy for proximal gastric carcinoma: Japan clinical oncology group study JCOG 0110-MF. Jpn J Clin Oncol 2002;32:363-4.

50. Siewert JR, Stein HJ. Adenocarcinoma of the gastroesophageal junction. Classification, pathology and extent of resection. Dis Esoph 1996;9:173-82.

51. Sasako M, Sano T, Yamamoto S, Sairenji M, Arai K, Kinoshita $\mathrm{T}$, et al. Left thoracoabdominal approach versus abdominaltranshiatal approach for gastric cancer of the cardia or subcardia: a randomised controlled trial. Lancet Oncol 2006;7:644-51.

52. Hulscher JB, van Sandick JW, de Boer AG, Wijnhoven BP, Tijssen JG, Fockens P, et al. Extended transthoracic resection compared with limited transhiatal resection for adenocarcinoma of the esophagus. N Engl J Med 2002;347:1662-9.

53. Omloo JM, Lagarde SM, Hulscher JB, Reitsma JB, Fockens P, van Dekken $\mathrm{H}$, et al. Extended transthoracic resection compared with limited transhiatal resection for adenocarcinoma of the mid/ distal esophagus: five-year survival of a randomized clinical trial. Ann Surg 2007;246:992-1000.

54. Ono H, Kondo H, Gotoda T, Shirao K, Yamaguchi H, Saito D, et al. Endoscopic mucosal resection for treatment of early gastric cancer. Gut 2001;48:225-9.

55. Park JC, Lee YC, Kim JH, Kim YJ, Lee SK, Hyung WJ, et al. Clinicopathological aspects and prognostic value with respect to age: an analysis of 3,362 consecutive gastric cancer patients. J Surg Oncol 2009;99:395-401.

56. Sue-Ling HM, Martin I, Griffith J, Ward DC, Quirke P, Dixon MF, et al. Early gastric cancer: 46 cases in one surgical department. Gut 1992;33:1318-22.

57. Jentschura D, Heubner C, Manegold BC, Rumstat B, Winkler M, Trede M. Surgery for early gastric cancer: a European onecennter experience. World J Surg 1997;21:845-9. 
58. Gotoda T. Endoscopic resection of early gastric cancer. Gastric Cancer 2007;10:1-11.

59. Katai H. Function-preserving surgery for gastric cancer. Int J Clin Oncol 2006;11:357-66.

60. Gotoda T, Yanagisawa A, Sasako M, Ono H, Nakanishi Y, Shimoda $\mathrm{T}$, et al. Incidence of lymph node metastasis from early gastric cancer: estimation with a large number of cases at two large centers. Gastric Cancer 2000;3:219-25.

61. Kurokawa Y, Hasuike N, Ono H, Boku N, Fukuda H. A phase II trial of endoscopic submucosal dissection for mucosal gastric cancer: Japan Clinical Oncology Group Study JCOG0607. Jpn J Clin Oncol 2009;39:464-6.

62. Seto Y, Shimoyama S, Kitayama J, Mafune K, Kaminishi M, Aikou $\mathrm{T}$, et al. Lymph node metastasis and preoperative diagnosis of depth of invasion in early gastric cancer. Gastric Cancer 2001;4:34-8.

63. Kunisaki C, Shimada H, Nomura M, Akiyama H. Appropriate lymph node dissection for early gastric cancer based on lymph node metastases. Surgery 2001;129:153-7.

64. Maekawa S, Takeo S, Ikejiri K, Anai H, Saku M. Clinicopathological features of lymph node metastasis in early gastric cancer. Int Surg 1995;80:200-3.

65. Kurihara N, Kubota T, Otani Y, Ohgami M, Kumai K, Sugiura $\mathrm{H}$, et al. Lymph node metastasis of early gastric cancer with submucosal invasion. Br J Surg 1998;85:835-9.

66. Ichikuara T, Uefuji K, Tomimatsu S, Okusa Y, Yahara T, Tamakuma S. Surgical strategy for patients with gastric carcinoma with submucosal invasion: a multivariate analysis. Cancer 1995; 76:935-40.

67. Ishigami S, Natsugoe S, Hokita S, Tokushige M, Saihara T, Watanabe T, et al. Carcinomatous lymphatic invasion in early gastric cancer invading into the submucosa. Ann Surg Oncol 1999;6:286-9.

68. Gotoda T, Sasako M, Ono H, Katai H, Sano T, Shimoda T. Evaluation of the necessity for gastrectomy with lymph node dissection for patients with submucosal invasive gastric cancer. Br J Surg 2001;88:444-9.

69. Morita S, Katai H, Saka M, Fukagawa T, Sano T, Sasako M. Outcome of pylorus-preserving gastrectomy for early gastric cancer. Br J Surg 2008;95:1131-5.

70. Hiki N, Sano T, Fukunaga T, Ohyama S, Tokunaga M, Yamaguchi T. Survival benefit of pylorus-preserving gastrectomy in early gastric cancer. J Am Coll Surg 2009;209:297-301.

71. Sawai K, Takahashi T, Fujioka T, Minato H, Taniguchi H, Yamaguchi T. Pylorus-preserving gastrectomy with radical lymph node dissection based on anatomical variations of the infrapyloric artery. Am J Surg 1995;170:285-8.

72. Isozaki H, Okajima K, Momura E, Ichinona T, Fujii K, Izumi N, et al. Postoperative evaluation of pylorus-preserving gastrectomy for early gastric cancer. Br J Surg 1996;83:266-9.

73. Nunobe S, Sasako M, Saka M, Fukagawa T, Katai H, Sano T. Symptom evaluation of long-term postoperative outcomes after pylorus-preserving gastrectomy for early gastric cancer. Gastric Cancer 2007;10:167-72.

74. Kodama M, Koyama K, Chida T, Arakawa A, Tur G. Early postoperative evaluation of pylorus-preserving gastrectomy for gastric cancer. World J Surg 1995;19:456-61.

75. Imada T, Rino Y, Takahashi M, Suzuki M, Tanaka J, Shiozawa M, et al. Postoperative functional evaluation of pylorus-preserving gastrectomy for early gastric cancer compared with conventional distal gastrectomy. Surgery 1998;123:165-70.

76. Shibata C, Shiiba KI, Funayama Y, Ishii S, Fukushima K, Mizoi $\mathrm{T}$, et al. Outcomes after pylorus-preserving gastrectomy for early gastric cancer: a prospective multicenter trial. World J Surg 2004;28:857-61.

77. Kodama M, Koyama K. Indications for pylorus preserving gastrectomy for early gastric cancer located in the middle third of the stomach. World J Surg 1991;15:628-33;

78. Kodera Y, Yamamura Y, Kanemitsu Y, Shimizu Y, Hirai T, Yasui $\mathrm{K}$, et al. Lymph node metastasis in cancer of the middle-third stomach: criteria for treatment with a pylorus-preserving gastrectomy. Surg Today 2001;31:196-203.

79. Katai H, Sano T, Fukagawa T, Shinohara H, Sasako M. Prospective study of proximal gastrectomy for early gastric cancer in the upper third of the stomach. Br J Surg 2003;90:850-3.

80. Furukawa H, Hiratsuka M, Imaoka S, Ishikawa O, Kabuto T, Sasaki Y, et al. Limited surgery for early gastric cancer in cardia. Ann Surg Oncol 1998;5:338-41.

81. Harrison LE, Karpeh MS, Brennan MF. Total gastrectomy is not necessary for proximal gastric cancer. Surgery 1998;123: 127-30.

82. Iwata T, Kurita N, Ikemoto T, Nishioka M, Andoh T, Shimada M. Evaluation of reconstruction after proximal gastrectomy: prospective comparative study of jejunal interposition and jejuna pouch interposition. Hepatogastroenterology 2006;53:301-3.

83. Ichikawa D, Ueshima Y, Shirono K, Kan K, Shioaki Y, Lee CJ, et al. Esophagogastrostomy reconstruction after limited proximal gastrectomy. Hepatogastroenterology 2001;48:1797-1801.

84. Takeshita K, Saito N, Saeki I, Honda T, Tani M, Kando F, Endo M. Proximal gastrectomy and jejunal pouch interposition for the treatment of early cancer in the upper third of the stomach: surgical techniques and evaluation of postoperative function. Surgery 1997;121:278-86.

85. Macdonald JS, Smalley SR, Benedetti J, Hundahl SA, Estes NC, Stemmermann GN, et al. Chemoradiotherapy after surgery compared with surgery alone for adenocarcinoma of the stomach or gastroesophageal junction. N Engl J Med 2001;345:725-30.

86. Cunningham D, Allum WH, Stenning SP, Thompson JN, Van de Velde CJ, Nicolson M, et al. Perioperative chemotherapy versus surgery alone for resectable gastroesophageal cancer. N Engl J Med 2006;355:11-20.

87. Sakuramoto S, Sasako M, Yamaguchi T, Kinoshita T, Fujii M, Nashimoto A, et al. Adjuvant chemotherapy for gastric cancer with S-1, an oral fluoropyrimidine. $\mathrm{N}$ Engl J Med 2007:357:1810-20.

88. Van Cutsem E, Kang Y, Chung H, Shen L, Sawaki A, Lordick F, et al. Efficacy results from the ToGA trial: a phase III study of trastuzumab added to standard chemotherapy (CT) in first-line human epidermal growth factor receptor 2 (HER2)-positive advanced gastric cancer (GC). Annual Meeting of ASCO 2009; abstract \#LBA4509.

89. Boku N. Chemotherapy for metastatic gastric cancer in Japan. Int J Clin Oncol 2008;13:483-7.

90. Kitagawa Y, Saikawa Y, Takeuchi H, Mukai M, Nakahara T, Kubo A, et al. Sentinel node navigation in early stage gastric cancer-updated data and current status. Scand J Surg 2006;95:256-9.

91. Aikou T, Kitagawa Y, Kitajima M, Uenosono Y, Bilchik AJ, Martinez SR, et al. Sentinel lymph node mapping with GI cancer. Cancer Metastasis Rev 2006;25:269-77.

92. Kitagawa Y, Takeuchi H, Takagi Y, Natsugoe S, Terashima M, Fujimura T, et al. Validation study of sentinel node mapping in gastric cancer: Prospective multicenter trial in Japan. Annual Meeting of ASCO Gastrointestinal Cancer Symposium 2010; abstract No: 1 . 